J. Dairy Sci. 92:3204-3210

doi:10.3168/jds.2008-1923

(c) American Dairy Science Association, 2009.

\title{
Technical note: Use of transfer RNA-intergenic spacer PCR combined with capillary electrophoresis to identify coagulase-negative Staphylococcus species originating from bovine milk and teat apices
}

\author{
K. Supré, ${ }^{* 1}$ S. De Vliegher, ${ }^{*}$ O. C. Sampimon,† R. N. Zadoks, $\ddagger^{2}$ M. Vaneechoutte,§ M. Baele,\# E. De Graef,\# \\ S. Piepers, ${ }^{*}$ and F. Haesebrouck\# \\ *Department of Reproduction, Obstetrics, and Herd Health, Faculty of Veterinary Medicine, Ghent University, Belgium \\ †Animal Health Service, Deventer, the Netherlands \\ ‡Quality Milk Production Services, Cornell University, Ithaca, NY \\ §Laboratory Bacteriology Research, Department of Clinical Chemistry, Microbiology, and Immunology, Faculty of Medicine, Ghent University, \\ Belgium \\ \#Department of Pathology, Bacteriology, and Avian Diseases, Faculty of Veterinary Medicine, Ghent University, Belgium
}

\section{ABSTRACT}

Coagulase-negative staphylococci (CNS) are the most frequently isolated bacteria in milk samples from cows with and without mastitis. Elucidating their relevance in bovine udder health is hampered because identification at the species level, if done at all, used to be performed based on phenotypic features. To provide a rapid, cheap, and easy-to-use genotypic technique that can be used to identify CNS species from milk and teat apices from cows, the performance of transfer RNA-intergenic spacer PCR (tDNA-PCR) in combination with capillary electrophoresis was evaluated. After updating the tDNA library with CNS reference strains, 288 field isolates were identified with tDNA-PCR and gene sequencing, and the latter was used as the reference method. The field isolates were divided in 2 groups of 144. Isolates of the first group were identified with tDNA-PCR with a typeability of $81.9 \%$ and an accuracy of $94.1 \%$. Peak patterns of these isolates were then added to the tDNA library with species identity as determined by DNA sequencing. The second group was identified with the updated tDNA library, resulting in $91.0 \%$ typeability and $99.2 \%$ accuracy. This study showed that the updated tDNA-PCR in combination with capillary electrophoresis was almost as accurate as gene sequencing but faster and cheaper (only $\$ 3$ per isolate), and is a useful tool in observational studies concerning the epidemiology of bovine CNS species.

Key words: bovine coagulase-negative staphylococci, milk, teat apex, transfer RNA-intergenic spacer polymerase chain reaction

Received November 24, 2008

Accepted March 16, 2009.

${ }^{1}$ Corresponding author: Karlien.Supre@UGent.be

${ }^{2}$ Current address: Royal (Dick) School of Veterinary Studies, University of Edinburgh, and Moredun Research Institute, Penicuik, Scotland.
The epidemiology and relevance of CNS as a cause of bovine mastitis is currently under debate. They have become the predominant pathogens found in milk samples from dairy cows and (fresh) heifers with and without mastitis. Descriptions of their pathogenicity and virulence vary from "protective organisms" and "harmless commensals" to "cause of subclinical mastitis" and "cause of (mild) clinical mastitis" (Piepers et al., 2007; Taponen et al., 2007; Schukken et al., 2009). Considering that there are many CNS species, the conflicting information on the effect of bovine CNS on udder health may be related to species-specific characteristics. Therefore, accurate species identification is a prerequisite to draw conclusions on the importance of CNS. Knowledge on the pathogenic or protective significance of individual CNS species will help formulate advice to farmers in case treatment or prevention is needed. Because commercial identification test kits such as StaphZym (Rosco, Taastrup, Denmark) and API Staph ID 32 (API Test, bioMérieux, Lyon, France) were designed on the basis of human isolates, they may fail to correctly identify CNS isolates of bovine origin (Heikens et al., 2005; Jousson et al., 2007; Sampimon et al., 2009). In addition, interpretation of results from conventional identification schemes and commercial test kits for CNS is subjective (Zadoks and Watts, 2009). Molecular identification methods offer accurate alternatives and are superior (Jousson et al., 2007). Sequencing of housekeeping genes was considered as the gold standard for identification of bacteria, including Staphylococcus species (Heikens et al., 2005; CLSI, 2007; Zadoks and Watts, 2009). For identification of large numbers of isolates, alternative methods with similar accuracy but faster turnaround and lower costs are preferable. Analysis of length polymorphism of the intergenic spacers between transfer $(\mathbf{t})$ RNA genes (tRNA-intergenic spacer PCR or tDNA-PCR) was used for identification of members of a range of bac- 
terial genera (Vaneechoutte et al., 1998; Baele et al., 2000, 2001). Enhancement of the discriminatory power by using the combination of tDNA-PCR with capillary electrophoresis (CE) has resulted in higher accuracy (Vaneechoutte et al., 1998; Baele et al., 2000, 2001). Nevertheless, this combination has never been used to identify CNS. When a PCR machine and CE equipment are available, tDNA-PCR in combination with $\mathrm{CE}$ is a user-friendly, inexpensive, and rapid method for species identification, provided that appropriate software is available for analysis of results.

The aim was to update our tDNA library using DNA sequence-based identification as the reference method, and to evaluate the typeability and accuracy of identification of CNS species from bovine milk and teat apices by means of tDNA-PCR typing.

Sixty-six reference Staphylococcus strains belonging to 27 species (Table 1) were used to create a tDNA-PCR fingerprint library. Staphylococcus caseolyticus was also included, although this species has been reclassified as Macrococcus caseolyticus (Kloos et al., 1998). In a next step, 288 bovine field isolates were identified using tDNA-PCR and gene sequencing. The isolates originated from 1) teat apex swabs from Flemish and Dutch dairy heifers taken between 8 and 2 wk before parturition $(\mathrm{n}=95) ; 2$ ) milk samples from Flemish dairy heifers collected between 1 and $4 \mathrm{~d}$ after calving $(\mathrm{n}=19)$; and 3) milk samples from Dutch dairy cows and heifers suffering from clinical or subclinical mastitis $(\mathrm{n}=174)$. All available field isolates were presumptively identified as CNS according to routine phenotypic procedures following National Mastitis Council guidelines (Hogan et al., 1999). Briefly, for analysis of milk samples, an inoculum of $0.01 \mathrm{~mL}$ of milk was spread on an esculin blood agar plate (Gibco Technologies, Paisley, UK). Plates were incubated aerobically at $37^{\circ} \mathrm{C}$ and examined after 24 and $48 \mathrm{~h}$. Teat apex swabs were inoculated onto Columbia blood agar plates (Gibco Technologies), which were incubated at $37^{\circ} \mathrm{C}$ and examined after 24 h. Staphylococcus species were differentiated from other bacteria by morphology, catalase and coagulase production, detection of hemolysis, and other biochemical properties. DNA was prepared by alkaline extraction as described by Baele et al. (2000). Supernatants were directly used as DNA extracts for both tDNA-PCR and gene sequencing or stored at $-20^{\circ} \mathrm{C}$ until further use.

All field isolates were subjected to sequencing of the rpoB ( $\beta$-subunit of RNA polymerase) gene. An isolate was identified when there was $94 \%$ or more sequence similarity with GenBank sequences of one species (Mellman et al., 2006). If this condition was not fulfilled, additional sequencing of $h s p 60$ (heat-shock protein 60 ) was performed with a threshold value of $97 \%$ for sequence similarity. If the $h s p 60$ sequence of an isolate had less than $97 \%$ similarity with one of the GenBank entries, or if GenBank sequences from multiple species showed more than $97 \%$ similarity as suggested by Zadoks and Watts (2009), 16S rRNA sequencing was performed. Criteria used for 16S rRNA sequencing were as described by Jousson et al. (2007); that is, an isolate was identified when there was $98.7 \%$ or more sequence similarity with one of the online sequences. If this condition was not fulfilled, sequencing of the tuf (elongation factor $\mathrm{Tu}$ ) gene was carried out with interpretation criteria as described for $h s p 60$. Additional genes were sequenced in the same order (i.e., hsp60 after rpoB, $16 \mathrm{~S}$ rRNA after $h s p 60$, and tuf after $16 \mathrm{~S}$ rRNA) if the amplification or sequencing reaction for a gene failed despite 3 -fold testing.

The 3 subsets of isolates from teat apex swabs, Flemish heifer milk samples, and Dutch milk samples were randomly divided into 2 groups using an Excel RAND function (Excel, 2007; Microsoft Corp., Redmond, WA). One group ( $\mathrm{n}=144$ isolates) was used to update the tDNA-PCR library, which only contained information from reference strains at that time. In this step, DNA sequence data were used to define the species identity of each field isolate. Sequences from the first group of isolates that were absent in GenBank were used to update the GenBank sequence database. The second group ( $\mathrm{n}=144$ isolates) was used to evaluate the final performance of the tDNA-PCR system and library after this update.

Techniques used to sequence the isolates from milk samples of the Dutch dairy cows and heifers were as described by Sampimon et al. (2009). Isolates from teat apices and milk of Flemish dairy heifers were analyzed as follows. Sequencing of the rpoB gene was performed as described by Drancourt and Raoult (2002) with small modifications (the annealing temperature was $48^{\circ} \mathrm{C}$ instead of $50^{\circ} \mathrm{C}$ ). The final products were separated on a capillary sequencer (ABI Prism 3100 Genetic Analyzer, Applied Biosystems, Foster City, CA). Forward and reverse sequences were aligned with the Vector NTI Advance 10 software (Invitrogen Life Technologies, Merelbeke, Belgium) and compared with GenBank sequences available online using nucleotide-nucleotide BLAST (http://ncbi.nlm.nih.gov/). Sequencing of the hsp60 gene was performed as described by Zadoks et al. (2005) with primers as used by Goh et al. (1997). Amplification of the 16S rRNA gene was performed with the primers 5 '-AGT TTG ATC CTG GCT CAG$3^{\prime}$ and $5^{\prime}$-TAC CCT GTT ACG ACT TCG TCC CA-3'. For the $16 \mathrm{~S}$ sequencing reaction, 4 primers were used in combination (5'-GTT GCG CTC GTT GCG GGA CT-3', 5'-GTA TTA CCG CGG CTG CG-3', 5'-CTC CTA CGG GAG GCA GCA GT-3', and 5'-AAC TCA AAG AA TTG ACG G-3'). For sequencing of the tuf 
Table 1. Reference strains used to construct the original transfer DNA-PCR library ${ }^{1}$

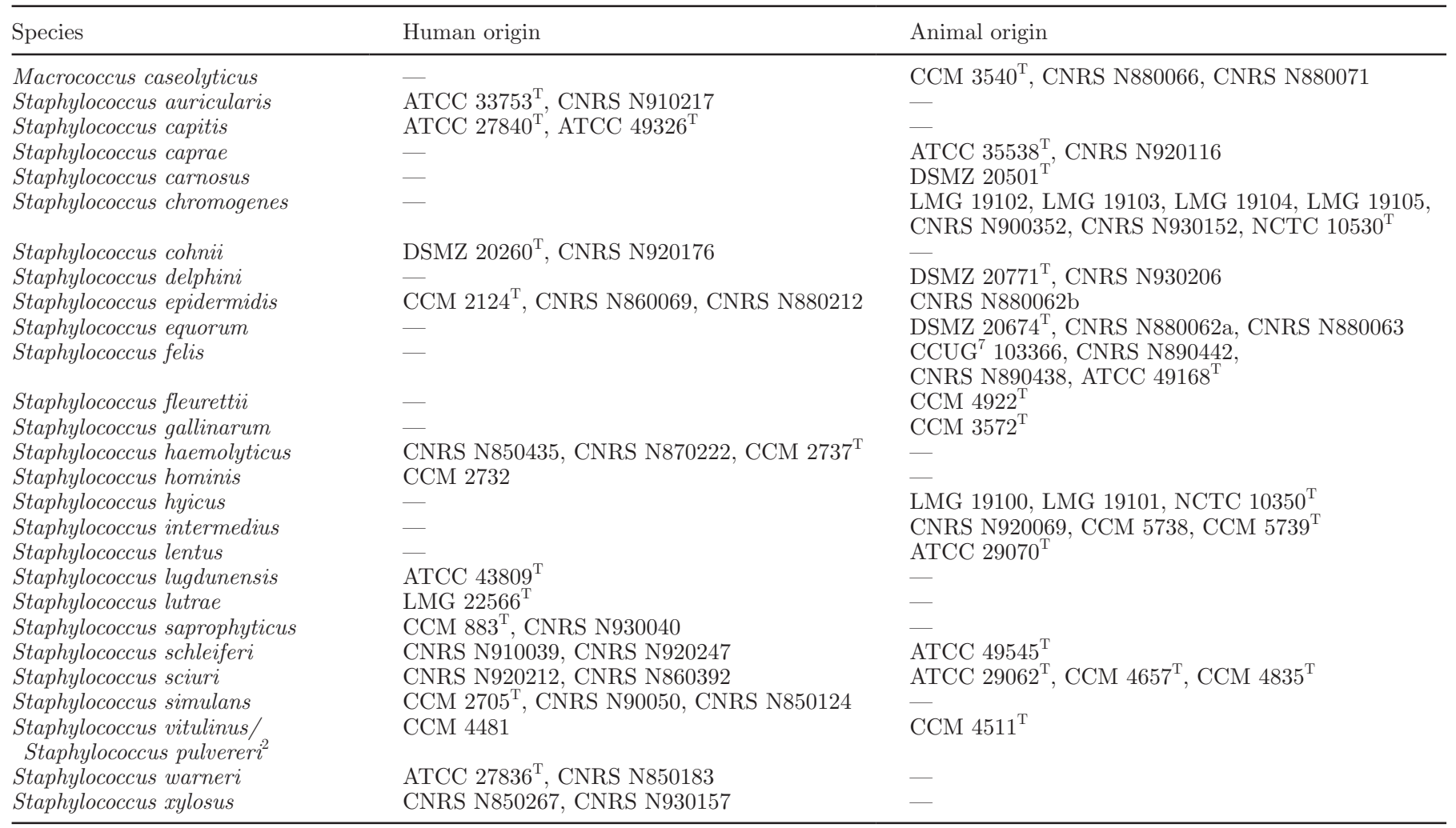

${ }^{1} \mathrm{CCM}=$ Czech Collection of Microorganisms, Prague, Czech Republic; CNRS = Centre National de Référence des Staphylocoques, Lyon, France; ATCC = American Type Culture Collection, Rockville, MD; DSMZ = Deutsche Sammlung von Mikroorganismen und Zellkulturen, Weringerode, Germany; LMG = Laboratory of Microbiology, Ghent University, Ghent, Belgium; NCTC = National Collection of Type Cultures, London, UK; and CCUG = Culture Collection, University of Göteborg, Göteborg, Sweden; ${ }^{\mathrm{T}}=$ type strain.

${ }^{2}$ Staphylococcus pulvereri was reclassified as Staphylococcus vitulinus in 2004 (Svec et al., 2004).

gene, primer sequences and PCR conditions were as described previously (Heikens et al., 2005).

All 288 field isolates were subjected to tDNA-PCR using the universal primers T5A (5'-AGTCCGGTGCTCTAACCAACTGAG-3') and T3B (5'-AGGTCGCGGGTTCGAATCC-3') (Welsh and McClelland, 1991) to amplify the spacer regions in between tRNA genes. Primer T3B consisted of a mixture of $4 / 5$ unlabeled and $1 / 5$ tetrachloro- 6 -carboxyfluorescine (TET)-labeled oligonucleotides to enable visualization with electrophoresis on a capillary sequencer (Vaneechoutte et al., 1998). The PCR mixtures and conditions were as described by Baele et al. (2000) with an annealing temperature of $48^{\circ} \mathrm{C}$. For $\mathrm{CE}$, the size standard mixture, containing $0.3 \mu \mathrm{L}$ of HD-400 and 0.2 $\mu \mathrm{L}$ of GS-500 (Applied Biosystems), was supplemented with $12 \mu \mathrm{L}$ of deionized formamide. After adding $1 \mu \mathrm{L}$ of PCR product, the resulting mixture was heated for $3 \mathrm{~min}$ at $95^{\circ} \mathrm{C}$ and cooled on ice for at least $15 \mathrm{~min}$. Capillary electrophoresis was performed using an ABI Prism 310 Genetic Analyzer (Applied Biosystems) at a constant voltage of $1.5 \mathrm{kV}$ at $60^{\circ} \mathrm{C}$. The capillaries were filled with Performance Optimized Polymer 4 (Applied Biosystems). The obtained electropherograms, after adjusting on the basis of the internal size standards, consisted of peaks that represented amplified tRNAintergenic spacer fragments with a length between 50 and 500 bp. Peaks that were lower than $50 \%$ of the average peak height were eliminated from the sample file derived from the Genescan software (Applied Biosystems). The resulting sample files were compared with the library (constructed as described below) of tDNA fingerprints of Staphylococcus species, using the in-house software as described previously (Baele et al., 2000, 2001; software available upon request from the authors). The distance matrix was calculated by the in-house software using the differential base pairs algorithm and clustering was done with the Neighbor algorithm. Visualization of dendrograms was carried out with Treeview software (http://taxonomy.zoology. gla.ac.uk/rod/treeview.html).

To construct a library, the 66 reference strains and M. caseolyticus (Table 1) were analyzed by tDNA-PCR. Every strain was analyzed twice to exclude small differ- 


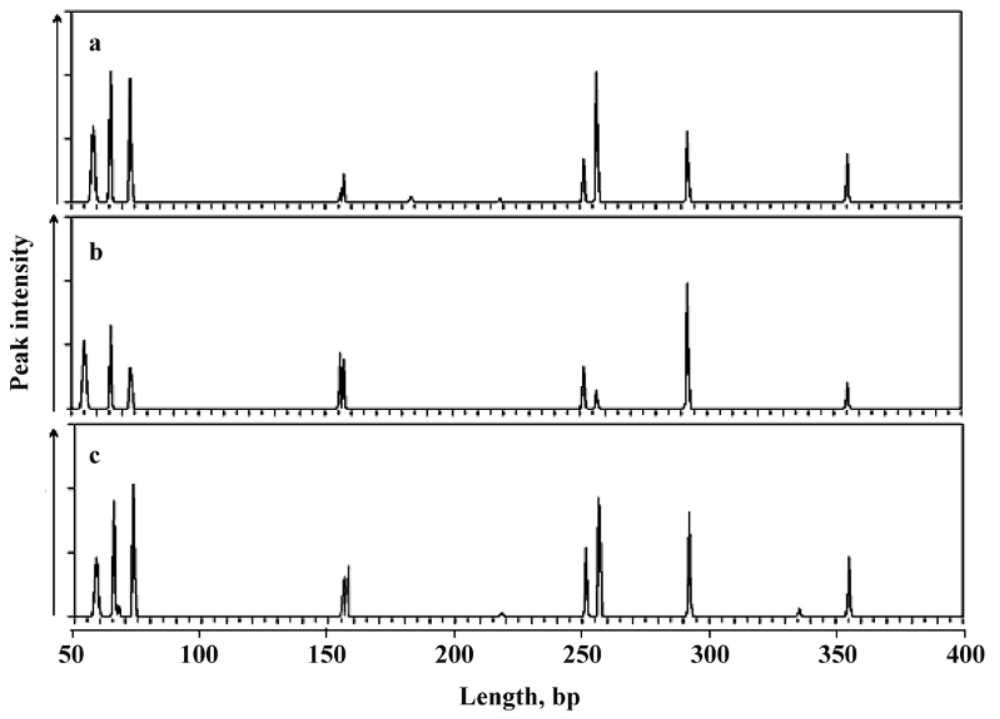

\begin{tabular}{|c|c|c|c|c|c|c|c|c|c|c|c|c|c|c|}
\hline Peak & 1 & 2 & 3 & 4 & 5 & 6 & 7 & 8 & 9 & 10 & 11 & 12 & 13 & 14 \\
\hline $\mathbf{a}$ & 55.1 & & 65.5 & & 73.4 & 155.6 & 157.1 & & & 251.4 & 256.7 & 292.4 & & 355.2 \\
\hline b & & 58.7 & 65.4 & & 73.3 & 155.6 & 157.1 & 183.7 & 218.5 & 251.4 & 256.7 & 292.4 & & 355.2 \\
\hline c & & 58.7 & 65.4 & 67.2 & 73.3 & 155.6 & 157.0 & & 218.4 & 251.6 & 256.8 & 292.3 & 335.6 & 355.2 \\
\hline Include & $\mathrm{No}^{1}$ & Yes & Yes & $\mathrm{No}^{1}$ & Yes & Yes & Yes & $\mathrm{No}^{1}$ & $\mathrm{No}^{2}$ & Yes & Yes & Yes & $\mathrm{No}^{1}$ & Yes \\
\hline Library & & 58.7 & 65.5 & & 73.3 & 155.6 & 157.1 & & & 251.5 & 256.7 & 292.4 & & 355.2 \\
\hline
\end{tabular}

Figure 1. Transfer (t)DNA-PCR fingerprint of 3 Staphylococcus chromogenes strains $\left(\mathrm{a}=\mathrm{NCTC} 10530^{\mathrm{T}} ; \mathrm{b}=\mathrm{LMG} 19103 ; \mathrm{c}=\mathrm{LMG} 19105\right)$ and the resulting $S$. chromogenes library entry based on these strains. The x-axis represents the fragment length in base pairs; the y-axis represents the peak intensity. Only one run per strain was taken in consideration for this example, whereas in the study each strain was run twice. In the table, footnote 1 indicates a peak excluded because it was not present in the majority of strains; footnote 2 indicates peak excluded because peak height was less than $50 \%$ of average.

ences between analyses. To have one pattern per species covering different strains per species, peaks that were not consistently present in the majority of strains within a species were left out of the library (Baele et al., 2000). Each entry consisted of a list of numerical values, representing the length of the different intergenic spacers (example given in Figure 1).

Typeability and accuracy were determined to evaluate the performance of tDNA-PCR. Typeability was defined as the percentage of isolates that could be assigned to a species by the typing system. Accuracy (defined as the correctness of the identification) was determined as the concordance of the tDNA identification with the reference method (CLSI, 2007; Zadoks and Watts, 2009).

The tDNA-PCR was performed on the first 144 isolates with a typeability of $81.9 \%$. Of the 118 isolates identified by tDNA-PCR, 7 isolates $(5.9 \%)$ belonging to different species were misidentified. This resulted in a concordance with gene sequencing of $94.1 \%$. When milk and teat apex isolates were considered separately, concordance was 95.2 and $91.4 \%$, respectively. After elimination of peaks lower than $50 \%$ of the average height of all peaks of the pattern of 1 isolate, all pat- terns were added to the tDNA library with species identity as determined by sequencing. Every field isolate accounted for one entry. After updating the tDNA library, the second group of field isolates was analyzed. Both typeability and accuracy improved considerably, namely 91.0 and $99.2 \%$ (98.9 for milk and $100 \%$ for teat apex isolates), respectively. One isolate $(0.7 \%)$ was misidentified; Staphylococcus chromogenes was identified as M. caseolyticus (Table 2). These results indicate that tDNA-PCR was almost as accurate as gene sequencing for identification of CNS field isolates. In addition, the assumption that differences in genetic profiles between isolates of varying hosts and origins can occur (Zadoks and Watts, 2009) was supported by the results; that is, tDNA-PCR scored better after adding field isolate patterns to the database. Libraries containing only type strains of human origin, which account for the greater part of most culture collections, were not sufficient to identify veterinary isolates. As the tDNA library did not contain the pattern of Staphylococcus nepalensis, a recently described species (Spergser et al., 2003), tDNA-PCR was not able to identify this species. Still, it was found in cow's milk based on gene sequencing results, and the peak pattern of this species was added to 
the tDNA library. This shows one of the advantages of online databases: they can be supplemented with data from studies conducted worldwide in a straightforward manner (CLSI, 2007; Zadoks and Watts, 2009). International cooperation would be valuable to determine whether the same tDNA library can be used in different laboratories for other batches of Staphylococcus field isolates from bovine or other origins. This would indicate the usefulness of an online tDNA library. Nonetheless, caution is needed when using online available reference data because the identification of deposited entries can be incorrect (Heikens et al., 2005; CLSI, 2007). In this study, sequences of the first group of isolates were analyzed twice: first comparing the field isolates with online sequences of only reference strains and then with all available sequences in the GenBank database. Because no difference in sequencing accuracy was seen, it was concluded that not only data from reference strains but also the complete GenBank database including field isolates could be used for sequencing analysis. Therefore, the complete GenBank database was used when analyzing the second group of isolates.

Gene sequencing was used as the reference method to update the tDNA library with CNS field isolates and to evaluate the technique. The typeability of successive sequencing of 4 genes for the isolates of the first group was $95.1 \%$. Sequence data that did not match our criteria for species identification, but that could be associated with a specific CNS species based on sequencing of additional genes were added to GenBank. After this was done, typeability based on sequence data for the second group of 144 isolates was 98.6\%. A disadvantage of tDNA-PCR might be the lower typeability (91.0\%) compared with sequencing, but the latter is only obtained after successive sequencing of 4 genes; that is, rpoB, hsp60, 16S rRNA, and tuf. When only rpoB sequencing was considered, $88.2 \%$ could be given identification, which was lower than the updated tDNA-PCR. The rpoB sequencing typeability was lower than expected. This was partly because of laboratory difficulties (i.e., no amplification or a failed sequencing reaction), even after 3 -fold testing starting from a new DNA extract. Because tDNA-PCR was scrutinized in this study, reasons for laboratory failure for sequencing procedures were not investigated. In this study, threshold values for tDNA-PCR to identify an isolate as a certain CNS species based on Treeview results were set at a minimum of $80 \%$. Setting a more tolerant value as threshold (e.g., at 50\%), as was done by Taponen et al. (2007) for amplified fragment length polymorphism clusters, would decrease the number of unidentifiable isolates. However, this would decrease the accuracy of differentiating CNS isolates belonging to closely related species, and this could be of more concern than limited typeability (Zadoks and Watts, 2009). To deal with the somewhat lower typeability of tDNA-PCR (or other techniques) without loss of accuracy, we would suggest performing additional molecular tests if necessary; for example, sequencing of one or more housekeeping genes.

To evaluate the practical usefulness in field studies with large numbers of isolates, the hands-on time of both techniques was compared. Starting from 48 pure cultures, hands-on time was 3.5 and $8 \mathrm{~h}$ for tDNA-PCR and sequencing, respectively, although greater automation could reduce the hands-on time of sequencing to $4 \mathrm{~h}$. Within $24 \mathrm{~h}$, tDNA results were available for up to 48 isolates (starting from pure cultures). Calculated costs for reagents and kits as used were less than $\$ 3$ per isolate for tDNA-PCR compared with $\$ 27$ for rpoB sequencing (starting from DNA extraction), although the cost of gene sequencing can be variable depending on laboratory circumstances ( $\$ 15$ to $\$ 27)$. The low cost, ease of use, and speed without substantial loss of accuracy compared with gene sequencing, were the greatest benefits of tDNA-PCR. Other PCR-based methods such as amplified fragment length polymorphism analysis have been used successfully for the identification of Staphylococcus species (Taponen et al., 2007). Those methods were more labor intensive and expensive, and validation was lacking. Species-specific PCR was developed for some CNS species from animal and human origin (Voytenko et al., 2006; Iwase et al., 2007), but these approaches should be tested on more and larger data sets. Ultimately, species-specific PCR could be developed, if needed, for the most relevant bovine CNS species.

In total, gene sequencing was unable to identify 15 out of 288 isolates to the species level, of which 11 were closely related based on their sequence similarities; tDNA-PCR recognized these as belonging to a separate species and further study is ongoing to confirm this represents a previously undescribed species. All new nucleotide sequences generated were deposited in the GenBank database under accession numbers FJ 234211 and FJ 389223 to FJ 389239 for rpoB; FJ 234212 and FJ 389210 to FJ 389222 for hsp60; FJ 389197 to FJ 389209 for 16S rRNA; and FJ 389240 to FJ 389249 for tuf sequences.

To our knowledge, the present paper was the first in which tDNA-PCR was combined with CE for the identification of bovine CNS using a manually constructed library based on type strains and updated with field isolates identified by means of a reference technique (gene sequencing). The use of $\mathrm{CE}$ made it possible to detect differences in fragment length as small as 1 $\mathrm{bp}$, enhancing the discriminatory power considerably (Vaneechoutte et al., 1998; Turenne et al., 1999), es- 
Table 2. Comparison of the identification of CNS isolates $(\mathrm{n}=144)$ from bovine milk and teat apices as obtained by transfer ( $\mathrm{t}$ )DNA-PCR (after the update of the tDNA library) and gene sequencing (rpoB, hsp60, 16S rRNA, and tuf genes)

\begin{tabular}{|c|c|c|c|c|c|c|c|c|c|c|c|c|c|c|c|c|c|c|c|}
\hline \multirow[b]{2}{*}{ tDNA-identification $^{1}$} & \multicolumn{19}{|c|}{ Sequencing identification } \\
\hline & No ID & Mcas & cap & $\operatorname{chr} r$ & coh & epi & equ & fle & haem & hyi & nep & sap & $s c i$ & sim & suc & war & $x y l$ & S_X ${ }^{2}$ & Total \\
\hline No identification (No ID) & 2 & 1 & & 3 & & 1 & & & 1 & 1 & 1 & & 1 & & & 1 & 1 & & 13 \\
\hline M. caseolyticus (Mcas) & & 3 & & 1 & & & & & & & & & & & & & & & 4 \\
\hline S. capitis (cap) & & & 3 & & & & & & & & & & & & & & & & 3 \\
\hline S. chromogenes (chr) & & & & 47 & & & & & & & & & & & & & & & 47 \\
\hline S. cohnii $($ coh $)$ & & & & & 2 & & & & & & & & & & & & & & 2 \\
\hline S. epidermidis (epi) & & & & & & 11 & & & & & & & & & & & & & 11 \\
\hline S. equorum (equ) & & & & & & & 10 & & & & & & & & & & & & 10 \\
\hline S. fleurettii (fle) & & & & & & & & 4 & & & & & & & & & & & 4 \\
\hline S. haemolyticus (haem) & & & & & & & & & 7 & & & & & & & & & & 7 \\
\hline S. hyicus (hyi) & & & & & & & & & & 8 & & & & & & & & & 8 \\
\hline S. nepalensis (nep) & & & & & & & & & & & & & & & & & & & 0 \\
\hline S. saprophyticus (sap) & & & & & & & & & & & & 1 & & & & & & & 1 \\
\hline S. sciuri (sci) & & & & & & & & & & & & & 8 & & & & & & 8 \\
\hline S. simulans (sim) & & & & & & & & & & & & & & 4 & & & & & 4 \\
\hline S. succinus (suc) & & & & & & & & & & & & & & & 3 & & & & 3 \\
\hline S. warneri (war) & & & & & & & & & & & & & & & & 3 & & & 3 \\
\hline S. xylosus ( $x y l$ ) & & & & & & & & & & & & & & & & & 10 & & 10 \\
\hline Staph spp. $\mathrm{X}^{2}\left(\mathrm{~S} \_\mathrm{X}\right)$ & & & & & & & & & & & & & & & & & & 6 & 6 \\
\hline Total & 2 & 4 & 3 & 51 & 2 & 12 & 10 & 4 & 8 & 9 & 1 & 1 & 9 & 4 & 3 & 4 & 11 & 6 & 144 \\
\hline
\end{tabular}


pecially for the identification of closely related species. The use of a capillary with liquid polymer instead of an agarose or polyacrylamide gel slab for the electrophoresis reduced variation caused by differences in the porosity of the gel (Maes et al., 1997; Taponen et al., 2007). The transformation of peak patterns into numerical values (i.e., automated digitization) enabled comparison with a library and eliminated subjective visual interpretation of peak or band patterns. Considering that the combination of tDNA-PCR with CE was almost as accurate, but faster, easier to use, and cheaper than gene sequencing, we conclude that this combination is a useful tool in large-scale observational studies aimed at elucidating the importance and epidemiology of bovine CNS species.

\section{ACKNOWLEDGMENTS}

This research was funded by the Institute for the Promotion of Innovation through Science and Technology in Flanders (IWT-Vlaanderen, grant no. 61459). The authors acknowledge the Dutch Udder Health Centre (Deventer, the Netherlands) for financially supporting part of the analyses.

\section{REFERENCES}

Baele, M., P. Baele, M. Vaneechoutte, V. Storms, P. Butaye, L. A Devriese, G. Verschraegen, M. Gillis, and F. Haesebrouck. 2000. Application of tRNA intergenic spacer PCR for identification of Enterococcus species. J. Clin. Microbiol. 38:4201-4207.

Baele, M., V. Storms, F. Haesebrouck, L. A. Devriese, M. Gillis, G. Verschraegen, T. De Baere, and M. Vaneechoutte. 2001. Application and evaluation of the interlaboratory reproducibility of tRNA intergenic length polymorphism (tDNA-PCR) for identification of species of the genus Streptococcus. J. Clin. Microbiol. 39:14361442.

CLSI (Clinical and Laboratory Standards Institute). 2007. Interpretive Criteria for Microorganism Identification by DNA Target Sequencing; Proposed Guideline. CLSI document MM18-P. Clinical and Laboratory Standards Institute, Wayne, PA.

Drancourt, M., and D. Raoult. 2002. rpoB gene sequence-based identification of Staphylococcus species. J. Clin. Microbiol. 40:1333-1338.

Goh, S. H., Z. Santucci, W. E. Kloos, M. Faltyn, C. G. George, D. Driedger, and S. M. Hemmingsen. 1997. Identification of Staphylococcus species and subspecies by the chaperonin 60 gene identification method and reverse checkerboard hybridization. J. Clin. Microbiol. 35:3116-3121.

Heikens, E., A. Fleer, A. Paauw, A. Florin, and A. C. Fluit. 2005. Comparison of genotypic and phenotypic methods for species-level identification of clinical isolates of coagulase-negative staphylococci. J. Clin. Microbiol. 43:2286-2290.

Hogan, J. S., R. N. Gonzáles, R. J. Harmon, S. C. Nickerson, S. P Oliver, J. W. Pankey, and K. L. Smith. 1999. Laboratory Handbook on Bovine Mastitis. Rev. ed. National Mastitis Council, Madison, WI.

Iwase, T., K. Seki, H. Shinji, Y. Mizunoe, and S. Masuda. 2007. Development of a real-time PCR assay for the detection and identification of Staphylococcus capitis, Staphylococcus haemolyticus and Staphylococcus warneri. J. Med. Microbiol. 56:1346-1349.
Jousson, O., D. Di Bello, M. Vanni, G. Cardini, G. Soldani, C. Pretti, and L. Intorre. 2007. Genotypic versus phenotypic identification of staphylococcal species of canine origin with special reference to Staphylococcus schleiferi subsp. coagulans. Vet. Microbiol. 123:238-244.

Kloos, W. E., D. N. Ballard, J. A. Webster, R. J. Hubner, W. Ludwig, K. H. Schleifer, F. Fiedler, and K. Schubert. 1998. Delimiting the genus Staphylococcus through description of Macrococcus caseolyticus gen. nov., comb. nov. and Macrococcus equipercicus sp. nov., Macrococcus bovicus sp. nov. and Macrococcus carouselicus sp. nov. Int. J. Syst. Bacteriol. 48:859-877.

Maes, N., Y. De Gheldre, R. De Ryck, M. Vaneechoutte, H. Meugnier, J. Etienne, and M. Struelens. 1997. Rapid and accurate identification of Staphylococcus species by tRNA intergenic spacer length polymorphism analysis. J. Clin. Microbiol. 35:2477-2481.

Mellmann, A., K. Becker, C. van Eiff, U. Keckevoet, P. Schumann, and D. Harmsen. 2006. Sequencing and staphylococci identification. Emerg. Infect. Dis. 12:333-336.

Piepers, S. L., L. De Meulemeester, A. de Kruif, G. Opsomer, H. W. Barkema, and S. De Vliegher. 2007. Prevalence and distribution of mastitis pathogens in subclinically infected dairy cows in Flanders, Belgium. J. Dairy Res. 74:478-483.

Sampimon, O. C., R. N. Zadoks, S. De Vliegher, K. Supré, F. Haesebrouck, H. W. Barkema, J. Sol, and T. J. G. M. Lam. 2009. Performance of API Staph ID 32 and Staph-Zym for identification of coagulase-negative staphylococci isolated from bovine milk samples. Vet. Microbiol. doi:10.1016/j.vetmic.2008.11.004

Schukken, Y. H., R. N. Gonzalez, L. L. Tikofsky, H. F. Schulte, G. C. Santisteban, F. L. Welcome, G. J. Bennett, M. J. Zurakowski, and R. N. Zadoks. 2009. CNS mastitis: Nothing to worry about? Vet. Microbiol. 134:9-14.

Spergser, J., M. Wieser, M. Taübel, R. A. Rosselló-Mora, R. Rosengarten, and H. J. Busse. 2003. Staphylococcus nepalensis sp. nov., isolated from goats of the Himalayan region. Int. J. Syst. Evol. Microbiol. 53:2007-2011.

Svec, P., M. Vancanneyt, I. Sedlacek, K. Engelbeen, V. Stetina, J. Swings, and P. Petras. 2004. Reclassification of Staphylococcus pulvereri Zakrzewska-Czerwinska et al. 1995 as a later synonym of Staphylococcus vitulinus Webster et al. 1994. Int. J. Syst. Evol. Microbiol. 54: 2213-2215.

Taponen, S., J. Koort, J. Björkroth, H. Saloniemi, and S. Pyörälä. 2007. Bovine intramammary infections caused by coagulasenegative staphylococci may persist throughout lactation according to amplified fragment length polymorphism-based analysis. J. Dairy Sci. 90:3301-3307.

Turenne, C. Y., S. E. Sanche, D. J. Hoban, J. A. Karlowsky, and A. M. Kabani. 1999. Rapid identification of fungi by using the ITS2 genetic region and an automated fluorescent capillary electrophoresis system. J. Clin. Microbiol. 37:1846-1851.

Vaneechoutte, M., P. Boerlin, H. V. Tichy, E. Bannerman, B. Jäger, and J. Bille. 1998. Comparison of PCR-based DNA fingerprinting techniques for the identification of Listeria species and their use for atypical Listeria isolates. Int. J. Syst. Bacteriol. 48:127-139.

Voytenko, A. V., T. Kanbar, J. Alber, C. Lämmler, R. Weiss, E. Prenger-Berninghoff, M. Zschöck, Ö. Akineden, A. A. Hassan, and O. A. Dmitrenko. 2006. Identification of Staphylococcus hyicus by polymerase chain reaction mediated amplification of species specific sequences of superoxide dismutase A encoding gene sodA. Vet. Microbiol. 116:211-216.

Welsh, J., and M. McClelland. 1991. Genomic fingerprints produced by PCR with consensus tRNA gene primers. Nucleic Acids Res. 19:861-866.

Zadoks, R. N., Y. H. Schukken, and M. Wiedmann. 2005. Multilocus sequence typing of Streptococcus uberis provides sensitive and epidemiologically relevant subtype information and reveals positive selection in the virulence gene pauA. J. Clin. Microbiol. 43:2407-2417.

Zadoks, R. N., and J. L. Watts. 2009. Species identification of coagulasenegative staphylococci: Genotyping is superior to phenotyping. Vet. Microbiol. 134:20-28. 